\section{Original Research}

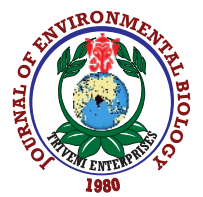

DOI : http://doi.org/10.22438/jeb/41/5/MRN-1215
Journal Home page : www.jeb.co.in ^ E-mail : editor@jeb.co.in Journal of Environmental Biology

p-ISSN: 0254-8704 e-ISSN: 2394-0379 CODEN: JEBIDP

\title{
Screening of marine Actinomycetes for inhibitory activity against biofilm forming bacteria
}

\author{
S. Kavitha ${ }^{1}$ and R. Vimala* \\ ${ }^{1}$ School of Biosciences and Technology, Vellore Institute of Technology, Vellore-632 014, India \\ ${ }^{2}$ Centre for Nanotechnology Research, Vellore Institute of Technology, Vellore-632 014, India \\ *Corresponding Author Email : vimala.r@vit.ac.in
}

\begin{abstract}
Aim: Marine ecosystem has served as an important source of economically and biotechnologically significant secondary metabolites. In view of this, the present study was carried out to isolate marine actinomycetes from rhizosphere soil sample and screen them for anti-microfouling activity.

Methodology: Screening of marine actinomycetes was done by agar well diffusion method and microtiter plate assay. The isolates with potent antimicrofouling activity were characterized by biochemical test and scanning electron microscopy. Finally, the isolates were identified by $16 \mathrm{~S}$ rRNA gene sequencing. The isolate VITKV6A showing maximum activity was subjected to mass cultivation and extraction of bioactive compounds using different solvents. The crude extract, thus, obtained was analyzed by GC-MS.

Results: Forty marine actinomycetes were isolated from rhizosphere soil sample of Rhizophora apiculata. Three isolates VITKV6A, VITKV7A and VITKV10A showing maximum activity were selected and subjected to morphological, cultural and molecular characterization. These isolates were identified as Streptomyces thermolineatus, Streptomyces variabilis and Streptomyces althioticus by $16 \mathrm{~S}$ rDNA sequencing. When tested for antimicrofouling activity, the chloroform extract of VITKV6A showed highest activity against all the three biofilm forming bacteria Psychrobacter celer, Psychrobacter alimentarius and Kocuria rhizophila used in this study. Gas chromatography-mass spectroscopic analysis of crude secondary metabolite extract from Streptomyces thermolineatus sp. (VITKV6A) was carried out and the results of the mass spectrum of compounds showed matches that were phenolic/polar molecules.
\end{abstract}

Interpretation: The results obtained indicate that bioactive compounds from marine actinomycetes would serve as potential anti-microfouling agent for control of microfouling caused in submerged environment.

Key words: Actinomycetes, Anti-microfouling, Biofilm, 16S rRNA

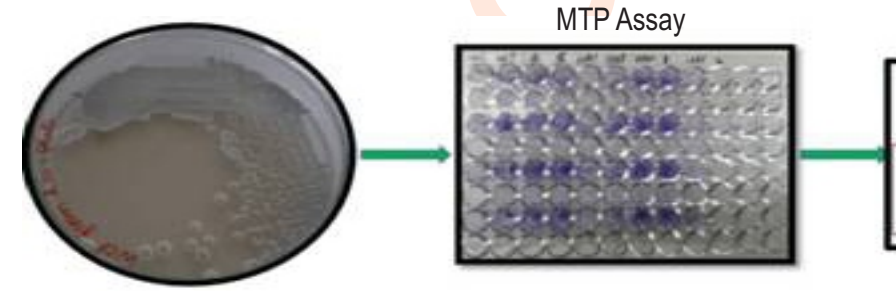

Isolation of marine actinomycetes

Screening for antimicrofouling activity
Phylogenetic tree

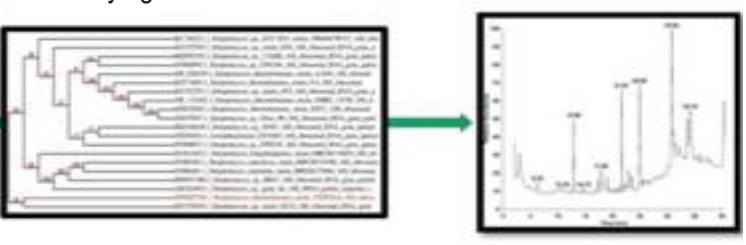

Identification of marine actinomycetes VITKV6A
GCMS analysis of crude extract from marine actinomycetes

How to cite : Kavitha, S. and R. Vimala: Screening of marine Actinomycetes for inhibitory activity against biofilm forming bacteria. J. Environ. Biol., 41, 995-1002 (2020). 


\section{Introduction}

Biofouling is referred to as the build-up of undesirable living organisms and several organic and inorganic compounds. In most of the cases, biofouling includes microscopic organic impurities or an observable slimy layer comprising bacteria and other microorganisms. This group of bio fouling is called microfouling, or more frequently biofilm, and occurs everywhere in both natural and industrial environments where surfaces are exposed to water (Costerton, 2017). When fully established, biofouling occuring in marine environment also includes macroscopic organisms, like algae and larvae of barnacles and other invertebrates causing problem for submerged structures, such as pipelines, cables, fishing nets, pillars of bridges and oil platforms and other port or hydrotechnical constructions (Railkin, 2004). Around $40 \%$ increase in fuel consumption of ships has been reported due to biofouling (Champ, 2000). In the following, we distinguish between "biofilm", including only microorganisms, and "biofouling", referring to fouling with both microscopic and macroscopic organisms. Since biofouling in the marine environment is initiated by a conditioning film consisting of organic compounds followed by initial colonizers such as bacteria and microalgae, curtailing microfouling will be an effective approach to check the subsequent steps leading to biofouling (Abarzua and Jakubowski, 1995). Conventional approaches to marine biofouling control through application of antifouling paints depend on the release of toxins that kill adhering organisms. Hitherto, tributyltin (TBT) and tributyltin oxide are the most active solutions to control biofouling but they are highly toxic (Shan et al., 2011). Antifouling paints encompassing irgarol, chlorothalonil, dichlofluanid and diuron are used against fouling organisms, but these antifoulants have been reported to cause extensive pollution due to their toxic effects on non-target organisms (Champman et al., 2014; Ji Young and Myoung Sug, 2012). Current efforts have been focussing on substituting environmentally persistent toxins with naturally derived, degradable repulsive, eco-friendly compounds (Yebra et al., 2004). There have been several studies demonstrating the presence of biologically active secondary metabolites in marine organisms such as actinomycetes ((Abid et al., 2016), sponges (Tsukamoto et al., 1997), corals (Clare et al., 1999; Qi et al., 2008) and algae (Dworjanyn et al., 2006). Nevertheless, the supply concern of these antifouling compounds often hinders their commercial application (Dobretsov et al., 2006). Compared to other group of microorganisms marine actinomycetes have received little attention in the search for anti-fouling agents. Moreover, the supply of bioactive metabolites and the cultivability of actinomycetes may not be a limiting factor. Therefore, isolation of marine actinomycetes capable of producing bioactive compounds with anti-microfouling potential will be a valuable endeavour. The objective of the present study was the isolation, characterization and identification of marine actinomycetes and screening for their anti-fouling potential.

\section{Materials and Methods}

Collection of sample: Rhizosphere soil sample of Rhizophora apiculata was collected from Pichavaram estuary, Parangipettai, Chidhambaram, Tamil Nadu. Sample was obtained from offshore at a depth of 2 to $3 \mathrm{~m}$. Samples were placed in sterile poly bags, sealed tightly, and transported immediately to the laboratory and kept in deep freezer until further processing.

Isolation of Actinomycetes: Ten gram of soil sample was dispensed in $100 \mathrm{ml}$ of sterile water and kept in shaker for $30 \mathrm{~min}$ at room temperature. Suspension dilutions were made upto $10^{-4}$ dilution. About $100 \mu$ l of suspension was spread on the surface of different agar media and incubated at $28^{\circ} \mathrm{C}$ for 7 days. Three different media viz. starch casein agar, yeast malt extract agar, Streptomyces Agar were used for isolation of actinomycetes isolates. Selected colonies were purified and maintained on slants of starch casein agar at $4^{\circ} \mathrm{C}$ for further studies.

Screening of Actinomycetes for anti-microfouling potential: Screening of Actinomycetes for anti-microfouling potential was carried out by agar well diffusion assay and microtier plate assay against three biofilm forming bacteria Psychrobacter celer, Psychrobacter alimentarius and Kocuria rhizhophila which were isolated earlier (Kavitha and Vimala 2018). Their biofilm forming ability was demonstrated by microtiter plate assay following the procedure of Jordjevic et al. (2002).

In agar well diffusion assay, isolates of marine actinomycetes were inoculated in Tryptone Yeast Extract broth and incubated at $28^{\circ} \mathrm{C}$ for 7 days. The culture broth was centrifuged at $10,000 \mathrm{rpm}$ for $15 \mathrm{~min}$ to obtain the culture supernatant. The test organisms were cultured in Zobell marine broth for $24 \mathrm{hr}$ and a lawn culture was made on Mueller Hinton agar plates. Wells of $6 \mathrm{~mm}$ diameter were made on each plate and loaded with the culture supernatant of actinomycetes isolates. The plates were then incubated at $37^{\circ} \mathrm{C}$ for $24 \mathrm{hr}$ and the zone of inhibition was measured.

To determine anti-biofilm activity of isolates, $40 \mu \mathrm{l}$ culture broth of biofilm forming bacterial strains were inoculated into polystyrene 96-well microtiter plates containing nutrient broth $(60 \mu \mathrm{l})$ and $100 \mu \mathrm{l}$ culture supernatant of marine actinomycete. The inoculated microtiter plates were incubated at $37^{\circ} \mathrm{C}$ for 3 days. Instead of supernatant, tryptone yeast extract broth was used as untreated control. After incubation, the planktonic cells and supernatant were removed and the adhered cells which formed the biofilm were rinsed and fixed with methanol and air dried. The biofilms were stained with $100 \mu \mathrm{l} 0.1 \%$ (w/v) crystal violet for $10 \mathrm{~min}$. The stain was discarded and the wells were rinsed with distil led water and solubilized with $99 \%$ ethanol. The optical densities of biofilm were determined using microtiter plate reader (Bio-Rad, USA) at $595 \mathrm{~nm}$ which corresponds to the amount of biofilm. 


\section{Characterization of Isolates:}

Morphological characterization: The morphological characterization of active isolates was carried out by inoculating them in different sterile media viz. starch casein agar (SCA), yeast malt extract agar (YMEA) and Streptomyces Agar. Colony morphology was observed with respect to color, aerial and substrate mycelium. Gram staining and scanning electron microscopic analysis of isolates were also carried out.

Biochemical characterization: Gram positive isolates were selected and subjected to biochemical characterization viz. starch hydrolysis, casein hydrolysis, gelatin hydrolysis, urea hydrolysis, citrate utilization test, indole test, Voges-Proskauer test, triple sugar ion test.

Molecular characterization: Molecular identification was carried out by $16 \mathrm{~S}$ rRNA gene sequencing. Genomic DNA was extracted, and amplified using 8F-(5'AGAGTTTGATCCTGGCT CAG3') with 20 base pairs, and 1541R - (5'AAGGAGGTG ATCCAGCCGCA3') with 20 base pairs. Polymerase chain reaction was performed by adding $5 \mu$ l of isolated DNA in $25 \mu$ of PCR reaction solution (1.5 $\mu$ l of Forward Primer and Reverse Primer, $5 \mu$ l of deionized water, and $12 \mu$ of Taq Master Mix). PCR product was sequenced using primers. Sequencing reactions were performed using ABI PRISM BigDyeTM Terminator Cycle Sequencing Kit with AmpliTaq DNA polymerase (FS enzyme) (Applied Biosystems). Single-pass sequencing was performed on each template using $16 \mathrm{~S}$ rRNA universal primers. The fluorescent-labeled fragments were purified from the unincorporated terminators with an ethanol precipitation protocol. The samples were suspended in distilled water and subjected to electrophoresis in an $\mathrm{ABI} 3730 \mathrm{xl}$ sequencer (Applied Bio systems).

Mass culture and extraction of bioactive compounds: Actinomycete isolates showing maximum activity were subjected to solvent extraction by liquid-liquid extraction method. The isolate was cultivated in $500 \mathrm{ml}$ Erlenmeyer flasks containing 200 $\mathrm{ml}$ of ISP1 medium. The culture flasks were incubated at $30^{\circ} \mathrm{C}$ for 7 days on an orbital shaker (150 rpm). The culture broth was then centrifuged for $15 \mathrm{~min}$ at $8000 \mathrm{rpm}$ to separate the culture supernatant. The supernatant was then divided into three equal volumes and extracted with equal volume of different organic solvents. Three different organic solvents ranging from polar to non-polar (ethyl acetate, chloroform and pet ether) were screened for effectiveness. The organic phases were evaporated to dryness using a Rota vapor (Laborota 4000).

In order to select the best extraction solvents, based on their anti-microfouling activity, the activity of each crude extract of selected isolates were examined. Briefly, each crude extract was subjected to agar well diffusion assay and microtiter plate assay against biofilm forming bacteria. Solvent showing highest inhibition diameter and highest anti-biofilm activity was then used for further extraction of active compounds.

Gas chromatography-mass spectrometry (GC-MS) analysis of crude extract: The crude extracts obtained from marine actinomycete isolates were analyzed in GC-MS JEOL (GCMTE II GC-MS, Agilent Technologies 6890N Network GC system for GC) equipped with a HP 5 fused silica column of $50 \mathrm{~m} \times 0.25 \mathrm{~mm}$ internal diameter based on the method described by Kushwaha et al. (2019). The analysis conditions were $20 \mathrm{~min}$ at $100^{\circ} \mathrm{C}, 3 \mathrm{~min}$ at $235{ }^{\circ} \mathrm{C}$ for column temperature and $240{ }^{\circ} \mathrm{C}$ for injector temperature. Helium was the carrier gas, and split ratio was 5:4. The sample $(1 \mu \mathrm{l})$ was injected in a split less mode at $300^{\circ} \mathrm{C}$. Run time was $30 \mathrm{~min}$. The compounds were identified by gas chromatography coupled with mass spectroscopy. The molecular weight and structure of the compounds were ascertained by matching with reference compounds available in the National Institute Standard and Technology (NIST).

\section{Results and Discussion}

Intense research has been carried out on actinomycetes isolated from several unexplored extreme environment (PathomAree et al., 2006; Le Roes-Hill et al., 2009; Li et al., 2011). Studies carried out in the past have stated that coastal areas of Tamil Nadu are rich in antifouling compounds producing actinobacteria. Manikandan and Vijayakumar (2016) isolated 20 actinomycetes possessing antibacterial activity against biofouling bacteria. Out of these isolates, one potent isolate VS6 was reported to show maximum activity against biofouling bacteria. Harir-Mohammed et al. (2017) in his report has demonstrated that actinomycetes from Sahara soils as potential source of novel antimicrobial compounds.

In the present study, rhizosphere soil sample of Rhizophora apiculata was collected and subjected to spread plate technique on different media. In total 40 actinomycetes isolates were obtained from the rhizosphere soil samples. Starch casein agar yielded good growth and highest number of actinomycete isolates compared to other media used in this study. This demonstrates that starch casein agar is the best medium for isolation of marine actinomycetes. Upon screening these 40 isolates for anti-microfouling activity, 8 isolates demonstrated activity against test organism viz., Psychrobacter celer, Psychrobacter alimentarius and Kocuria rhizophila. Among the eight isolates, VITKV6A, VITKV7A and VIT KV10A showed maximum zone of inhibition and higher anti-biofilm activity. The anti-microbial activities of all three isolates were found maximum against Kocuria rhizophila. The results of microtitre plate assay demonstrated that the biofilm inhibitory activity of VITKV6A against Psychrobacter celer, Psychrobacter alimentarius and Kocuria rhizophila (OD value of $1.9,1.2$ and 0.9 respectively) was highest compared to VITKV7A and VITKV10A. These three isolates were further subjected to morphological, biochemical and molecular characterization. 
Three potent isolates thus screened for anti-microfouling activity were subjected to morphological characterization. Gram staining of isolates showed positive with different morphological structures. They were rod shaped with fungus like branched networks of hyphae. Also, the morphological characterization of isolates on starch casein agar revealed the color of the colony, aerial and substrate mycelium. The aerial mycelium of VITKV6A was whitish grey whereas VITKV7A and VITKV10A showed grey color aerial mycelium. In case of substrate mycelium, it was observed that VITKV6A and VITKV10A showed white mycelium and VITKV7A showed grey mycelium.

The results of biochemical tests were positive for hydrolysis of starch, casein and gelatin, citrate utilization and triple sugar ion test for all the three actinomycetes isolates.

The molecular identification of VITKV6A, VITKV7A and VITKV10A was analyzed by $16 \mathrm{~S}$ rRNA. Obtained sequences were compared with the GenBank sequence using BLAST and aligned with the sequence retrieved from NCBI GenBank database using the Clustal method. By using neighbor joining tree method phylogenetic tree was constructed (Fig. $1 \mathrm{a}$, b and c) and the database was deposited in NCBI GenBank with their accession numbers MG062749. 1, MG062750. 1, MG062751. 1, respectively. Depending on the cultural, morphological, physiological, and molecular analysis, the strains were identified as Streptomyces thermolineatus, Streptomyces variabilis, and Streptomyces althioticus respectively.

Several attempts have been made for the isolation of actinomycetes from marine environment (Barcina et al., 1987). Recent studies have reported that members from marine environment belonging to several genera viz. Nocardia, Streptomyces and Dietzia (Rainey et al., 1995; Heald et al.,
2001), Streptomyces (Moran et al., 1995) and Marinactinospora (Tian et al., 2009) are potential sources of bioactive compounds.

In a previous study, Xu et al. (2009) reported isolation of antifouling compound from Streptomyces so UST040711-290. Isolated compound 12-methyltetradecanoid acid which is a branched-chain fatty acid was reported to deter the settlement of larvae, Hydroides elegans. A group of five structurally similar compounds were isolated from marine Streptomyces sp. and the anti-fouling activity of these compounds were compared with four other structurally related compounds isolated from North Sea Streptomyces (Xu et al., 2010). The structure-activity relationships showed that the functional moiety responsible for anti-fouling activity lies in 2-furanone ring. The findings of the study lead to the synthesis of a straight alkyl side-chain compound which was highly effective, non-toxic and capable of inhibiting the settlement of larvae of major fouling organisms. Marine sediments of Red Sea contain novel species of actinomycetes whose crude extracts show cytotoxic activity against breast cancer cell lines MDA-MB-231 (Abdelfattah1 et al., 2016). These strains have been identified as members of genera Streptomyces and Nocardiopsis. An organic extract derived from the marine sponge-associated bacterium Streptomyces sp. SBT343 significantly inhibited staphylococcal biofilm formation (Balasubramanian et al., 2017). Marine actinomycetes isolated from sea sediments of Andaman and the Gulf of Thailand inhibited biofilm formation by $E$. coli and $S$. aureus by protease activity (Leetanasaksakul and Thamchaipenet, 2018).

Culture filtrates containing secondary metabolites are usually complex mixtures, and the presence of different components may hinder the process of interpretation of data on bioactivity.

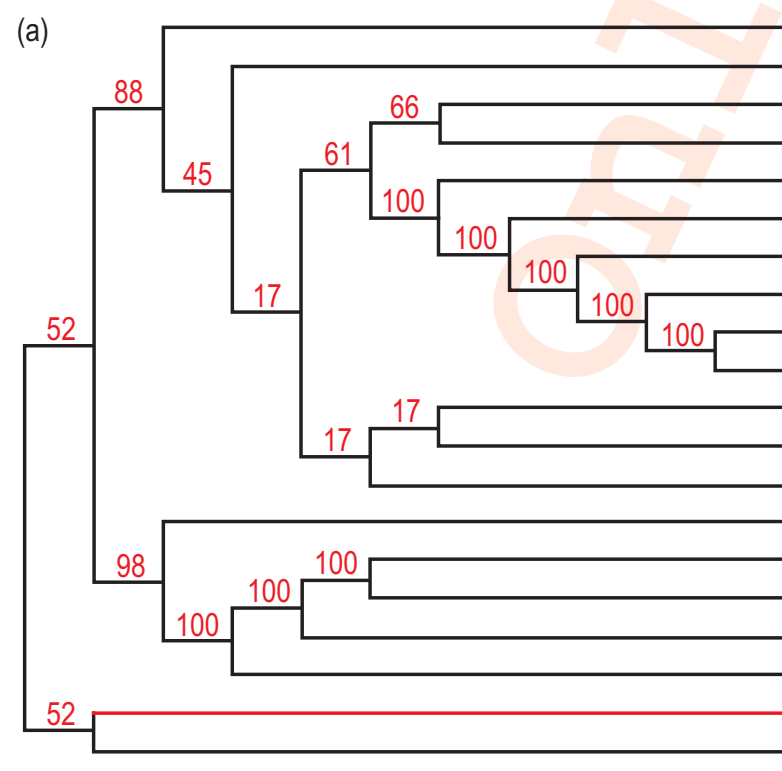

KC336221.1_Streptomyces_sp. ZZY-2013 strain_TRM46799-87_16S_rubo KX352765.1_Streptomyces_sp._strain_JJ16_16S_ribosomal_RNA_gene_p HQ992705.1_Streptomyces_sp._172660_16S_ribosomal_RNA_gene_partia JN968995.1_Streptomyces_sp._CPE184_16S_ribosomal_RNA_gene_partia NR_026529.1_Streptomyces_thermolineatus_strain_A1484_16S_ribosom KJ571064.1_Streptomyces_thermolineatus_strain_9-4_16S_ribosomal KX352767.1_Streptomyces_sp._strain_JJ19_16S_ribosomal_RNA_gene_p NR_112442.1_Streptomyces_thermolineatus_strain_NBRC_14750_16S_ri KP823658.1_Streptomyces_thermolineatus_strain_XD71_16S_ribosomal JX047047.1_Streptomyces_sp._O Act_90_16S_ribosomal_RNA_gene_parti DQ184648.1_Streptomyces_sp._M491_16S_ribosomal_RNA_gene_partial JN049454.1_Actinobacterium_ZXY005_16S_ribosomal_RNA_gene_partial JN969037.1_Streptomyces_sp._CPE510_16S_ribosomal_RNA_gene_partia EU841632.1_Streptomyces_bingchengensis_strain_HBUM174849_16S_rib FJ486382.1_Streptomyces_ramulosus_strain_HBUM174769_16S_ribosoma FJ486481.1_Streptomyces_catenulae_strain_HBUM175064_16S_ribosoma HM051280.1_Streptomyces_sp._BB47_16S_ribosomal_RNA_gene_partial AB184492.1_Streptomyces_sp._gene_for_16S_rRNA_partial_sequence_s MG062749.1_Streptomyces_thermolineatus_strain_VITKV6A_16S_riboso KX352810.1_Streptomyces_sp._strain_JJ124_16S_ribosomal_RNA_gene 
(b)

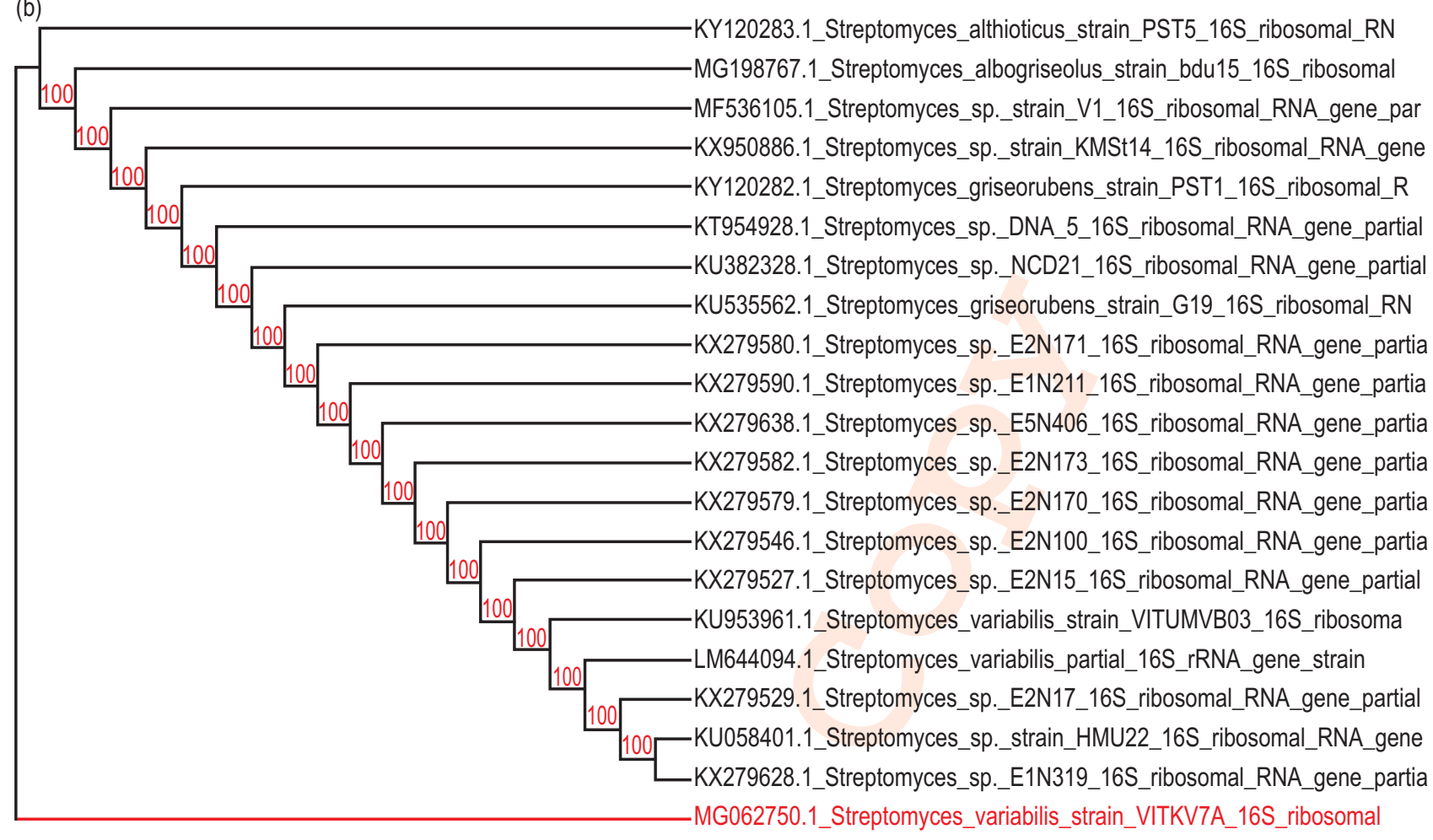

(c)

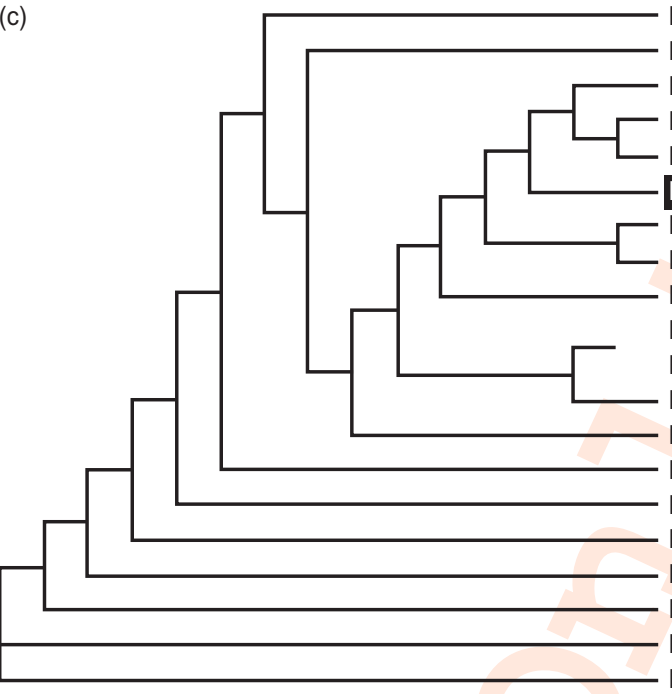

KX279580.1_Streptomyces_sp._E2N171_16S_ribosomal_RNA_gene_partial_sequence KX279628.1_Streptomyces_sp._E1N319_16S_ribosomal_RNA_gene_partial_sequence MG198767.1_Streptomyces_albogriseolus_strain_bdu15_16S_ribosomal_RNA_gene_part -MF536105.1_Streptomyces_sp._strain_V1_16S_ribosomal_RNA_gene_partial_sequence KY120283.1_Streptomyces_althioticus_strain_PST5_16S_ribosomal_RNA_gene_partial MG062751.1_Streptomyces_althioticus_strain_VITKV10A_16S_ribosomal_RNA_gene_par KX950886.1_Streptomyces_sp._strain_KMSt14_16S_ribosomal_RNA_gene_partial_seque KU535562.1_Streptomyces_griseorubens_strain_G19_16S_ribosomal_RNA_gene_partial KT898118.1_Streptomyces_sp._RA6_16S_ribosomal_RNA_gene_partial_sequence KY120282.1_Streptomyces_griseorubens_strain_PST4_16S_ribosomal_RNA_gene_partia KT954928.1_Streptomyces_sp._DNA_5_16S_ribosomal_RNA_gene_partial_sequence KU382328.1_Streptomyces_sp._NCD21_16S_ribosomal_RNA_gene_partial_sequence KU058401.1_Streptomyces_sp._strain_HMU22_16S_ribosomal_RNA_gene_partial_sequen KX279590.1_Streptomyces_sp._E1N211_16S_ribosomal_RNA_gene_partial_sequence KX279529.1_Streptomyces_sp._E2N17_16S_ribosomal_RNA_gene_partial_sequence KX279579.1_Streptomyces_sp._E2N170_16S_ribosomal_RNA_gene_partial_sequence KX279582.1_Streptomyces_sp._E2N173_16S_ribosomal_RNA_gene_partial_sequence KX279527.1_Streptomyces_sp._E2N15_16S_ribosomal_RNA_gene_partial_sequence KX279546.1_Streptomyces_sp._E2N100_16S_ribosomal_RNa_gene_partial_sequence KX279638.1_Streptomyces_sp._E5N406_16S_ribosomal_RNA_gene_partial_sequence

Fig. 1 : Phylogentic tree of (a) Streptomyces thermolineatus; (b) Streptomyces variabilis and (c) Streptomyces althioticus

Solvent extraction offers the ease of liquid handling, the potential for high throughput operation and the potential for adapting to continuous operation (Gailliot, 1998). Selection of the most appropriate solvent is an important step in extraction process. Commonly used water immiscible solvents include alcohols (n-butanol, isobutanol), ketones, acetates (butyl, ethyl, isopropyl), hydrocarbons (toluene, hexanes) and methylene chloride. Common water-miscible solvents are the alcohols particularly methanol. Both water-miscible and immiscible solvents are used for extracting compounds from the biomass. In this study, culture supernatant of VITKV6A was found to exhibit maximum activity was subjected to solvent extraction using three different solvents (ethyl acetate, chloroform and pet ether). The crude extracts thus obtained were subjected to anti-microfouling activities and the results showed that chloroform extract exhibited maximum zone of inhibition (Fig. 2) and anti-biofilm activity 


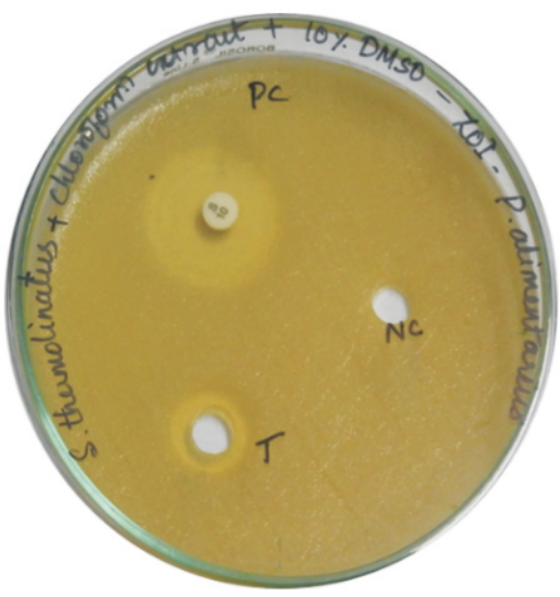

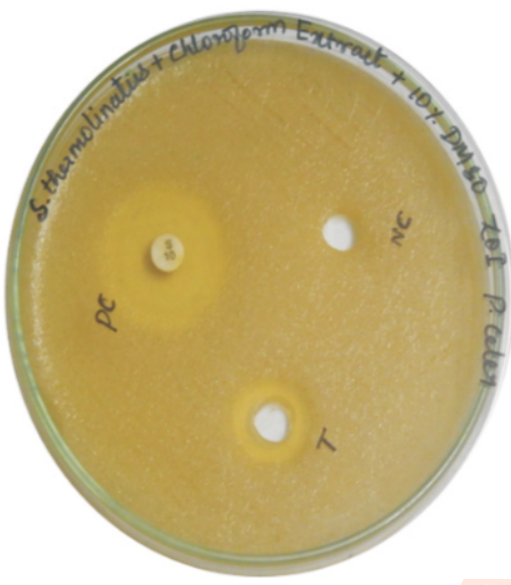

(b)

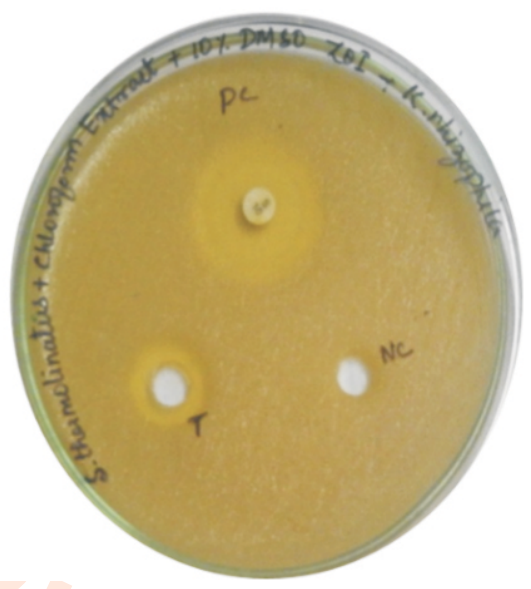

(c)

Fig. 2 : Antibacterial activity of the crude extract (Chloroform) of VITKV6A against biofilm forming bacteria by agar well diffusion method

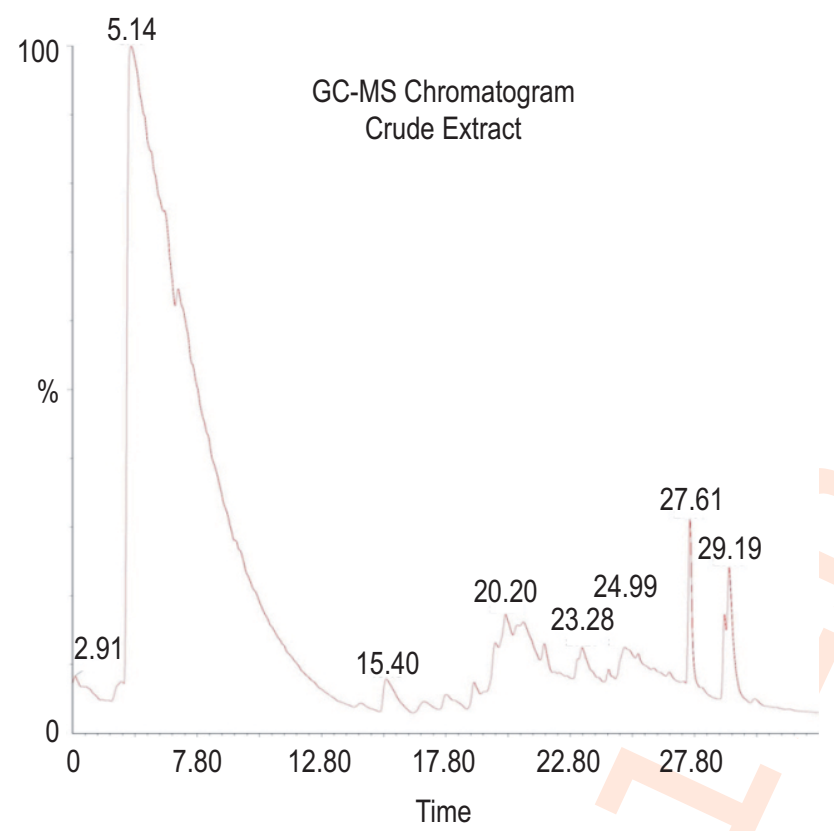

Fig. 3 : Chromatogram from Gas Chromatography - Mass Spectrometry analysis of the crude extract

against all the three biofilm forming bacteria. The zone of inhibition measures $14 \mathrm{~mm}, 15 \mathrm{~mm}$ and $16 \mathrm{~mm}$ for VITKV6A against $P$. celer, $P$. alimentarius $K$. rhizophila respectively. The results of antibiofilm activity were found in accordance with the zone of inhibition.

GC-MS analysis of crude secondary metabolite extract from Streptomyces thermolineatus (VITKV6A) showed multiple (>10 peaks) compounds throughout the chromatogram. The chromatogram of the GC-MS analysis is shown in Fig. 3. Among the observed peaks, five peaks at $20.20 \mathrm{~min}, 23.28 \mathrm{~min}, 24.99$ min, $27.61 \mathrm{~min}$ and $29.19 \mathrm{~min}$ RT (Retention Time) were significantly major with regard to their intensity. The area percentage compositions of these five major peaks in the studied crude extract was $5.085,2.258,4.085$ and 3.815 , respectively. NIST library search of the mass spectrum of these 5 compounds showed matches that were phenolic/polar molecules. NIST library match did not show any non-polar/hydrocarbon derivatives, suggesting that the studied crude extract mainly consists of polar molecules, corresponding to their initial extraction using chloroform solvent. The molecular weight and mass spectrum fragmentation pattern of these 5 compounds were completely different, with molecular weight ranging between $441.28 \mathrm{~g} \mathrm{~mol}^{-1}$ to $87.95 \mathrm{~g} \mathrm{~mol}^{-1}$. The GC-MS analysis along with NIST library match analysis provided an understanding of the molecular weight and nature of secondary metabolites in the crude extract, which can support further purification and identification of the active moiety. Research carried out by (Rangel-Sanchez et al., 2014) reported that the phenolic compound isolated from the Avocado roots possessed marked antifungal activity against a wide range of fungi. Studies carried out in the past have reported that phenolic compounds possess antioxidant activity take part in ROS scavenging. Phenol, 2, 4-bis (1, 1-dimethylethyl)-has been identified in Streptomyces cavouresis KUV39 isolated from vermicompost samples collected in India (Narendhran et al., 2014). The study also demonstrated that this compound could be probably responsible for the antioxidant and cytotoxic properties of Streptomyces cavouresis KUV39. Further, phenol, 2, 4-bis (1, 1-dimethylethyl) has also been isolated from Streptomyces sp. MUM256 and identified to exhibit potential antioxidant activity (Tan et al., 2015). A novel Streptomyces antioxidans reported by Ser et al. (2016) was found to produce phenol, 2, 4-bis (1, 1-dimethylethyl) which was detected in the extract.

Further studies on the optimization, isolation and identification of individual compound in order to have an insight into its interaction with the diverse marine ecosystem are in progress. This would also help in assessing the commercial applicability of anti-fouling compound. 
This study investigated the potential of marine actinomycetes in producing anti-micro fouling compounds and endorsed that rhizosphere soils of plants in mangrove forests can be considered as a distinctive natural source of anti-micro fouling agents. Thus marine actinomycetes could be a rich source of environmentally benign anti-micro fouling compounds.

\section{Acknowledgment}

The authors would like to thank Vellore Institute of Technology, Vellore, Tamil Nadu, for providing the facilities to carry out this research work.

\section{References}

Abarzua, S. and S. Jakubowski: Biotechnological investigation for the prevention of biofouling. I. Biological and biochemical principles for the prevention of biofouling. Mar. Ecol. Prog. Ser., 123, 301-312 (1995).

Abdelfattah, M. S., M.I.Y. Elmallah, U.W. Hawas, L.T.A. El-Kassema and M.A.G. Eid: Isolation and characterization of marine-derived actinomycetes with cytotoxic activity from the Red Sea coast. Asian Pac. J. Trop. Biomed., 6, 651-657 (2016).

Abid, A., R. Mujamammi and M.D.F. Alkahtani: Antimicrobial activity and molecular identification of Strptomyces strains isolated from Saudi Arabia. J. Environ. Biol., 37, 1225-1230 (2016).

Balasubramanian, S., E.M. Othman, D. Kampik, H. Stopper, U. Hentschel, W. Ziebuhr, T.A. Oelschlaeger and U.R. Abdelmohsen: Marine sponge-derived Streptomyces sp. SBT343 extract inhibits Staphylococcal biofilm formation. Front. Microbiol., 8, article 236, (2017). doi. 10.3389/fmicb.2017.00236.

Champ, M.: A review of organotin regulatory strategies pending actions related costs and benefits. Sci. Total Environ., 258, 21-71 (2000).

Chapman, J., C. Hellio, T. Sullivan, R. Brown, S. Russell, E. Kiterringham, L. Nor and F. Regan: Bioinspired synthetic macroalgae: Examples from nature for antifouling applications. Int. Biodeter. Biodegr., 86, 6-13 (2014).

Clare, A.S., D. Rittschof, D.J. Gerhart and J.S. Maki: Molecular approaches to nontoxic antifouling. J. Invert. Reprod. Dev., 22, 67-76 (1992).

Costerton, J.W.: The biofilm primer. Berlin, Heidelberg. Springer, Verlag (2007).

Dobretsov, S, H.U. Dahms and P.Y. Qian: Inhibition of biofouling by marine microorganisms and their metabolites. Biofouling, 22, 43-54 (2006).

Dworjanyn, S.A., R. de Nys and P.D. Steinberg: Chemically mediated antifouling in the red alga Delisea pulchra. Mar. Ecol. Prog, Ser., 318, 153-163 (2006).

Gailliot, F.P.: Initial Extraction and Product Capture: Natural Product Isolation. ${ }^{\text {st }}$ Edn., Humana Press, New Jersey, pp. 53-90 (1998).

Harir, M., B. Miloud, F. Zohra, J.M.G. Arenzana, A. Veloso and S.R. Couto: Isolation and charaterization of Actinobacteria from Algerian Sahara soils with antimicrobial activities. Int. J. Mol. Cell. Med., 6, 109-120 (2017).

Heald, S.C., P.F.B. Brandao, R. Hardicre and A.T. Bull: Physiology, biochemistry and taxonomy of deep-sea nitrile metabolising Rhodococcus strains. Antonie Van Leeuwenhoek, 80, 169-83 (2001)
Ji Young, C. and K.M. Sug: Induction of antifouling diterpene production by Streptomyces cinnabarinus PK209 in co-culture with marinederived Alteromonas sp. KNS-16. Biosci. Biotechnol. Biochem., 76, 1849-1854 (2012).

Jordjevic, D., M. Wiedmann and L.A. McLandsborough: Microtiter plate assay for assessment of Listeria monocytogenes biofilm formation. Appl. Environ. Microbiol., 68, 2950-2958 (2002).

Kavitha, S. and R. Vimala: Isolation and characterization of marine biofilm forming bacteria from a ship's hull. Front. Biol., 13, 208-214 (2018).

Kushwaha, P., S. Yadav, V. Singh and L.K. Dwivedi: Phytochemical screening and GC-MS studies of the methanolic extract of Tridax procumbens. Int. J. Pharm Sci. Res., 10, 2492-96 (2019).

Le Roes-Hill, M., J. Rohland, P. R. Meyers, D.A. Cowan and S.G. Burton: Streptomyces hypolithicus sp. nov., isolated from an Antarctic hypolith community. Int. J. Syst. Evol. Microbiol., 59, 2032-2035 (2009).

Leetanasaksakul, K. and A. Thamchaipenet: Potential anti-biofilm producing marine actinomycetes isolated from sea sediments in Thailand. Agri. Nat. Res., 52, 228-233 (2018).

Li, J., X.P. Tian, T.J. Zhu, L.L. Yang and W.J. Li: Streptomyces fildesensis sp. nov., a novel streptomycete isolated from Antarctic soil. Antonie van Leeuwenhoek, 100, 537-543(2011).

Manikandan, R. and R. Vijayakumar: Screening of antifouling compound producing marine actinobacteria against biofouling bacteria isolated from poultries of Namakkal District, South India. Res. J. Sci. Tech., 8, 1-7 (2016).

Moran, M.A., L.T Rutherfford and R.E. Hodson: Evidence for indigenous Streptomyces populations in a marine environment determined with a 16S rRNA probe. Appl. Environ. Microbiol., 61, 3695-700 (1995).

Narendhran, S., P. Rajiv, P. Vanathi and R. Sivaraj: Spectroscopic analysis of bioactive compounds from Streptomyces cavouresis kuv39. Evaluation of antioxidant and cytotoxicity activity. Int. J. Pharm. Pharm. Sci., 6, 319-322 (2014).

Pathom-Aree, W., J.E.M. Stach, A.C. Ward, K. Horikoshi, A.T. Bull and M. Goodfellow: Diversity of actinomycetes isolated from challenger deep sediment $(10,898 \mathrm{~m})$ from the Mariana trench. Extremophiles, 10, 181-189 (2006).

Qi, S.H., S. Zhang, L.H. Yang and P.Y. Qian: Antifouling and antibacterial compounds from the gorgonians Subergorgia suberosa and Scripearia gracillis. Nat. Prod. Res., 22, 154-166 (2008).

Railkin, A.I.: Marine biofouling: Colonization processes and defences: Boca Raton. CRC, Press LLC (2004).

Rainey, F.A., J. Burghardt, R.M. Kroppenstedt, S. Klatte and E. Stackebrandt: Phylogenetic analysis of the genera Rhodococcus and Nocardia and evidence for the evolutionary origin of the genus Nocardia from within the radiation of Rhodococcus species. Microbiology, 141, 523-528 (1995).

Rangel-Sanchez, G., E.C. Mercado and E.G. Pineda: Avocado roots treated with salicylic acid produce phenol-2, 4-bis (1, 1dimethylethyl), a compound with antifungal activity. J. Plant. Physiol., 171, 189-98 (2014).

Ser, H.L., L.T. Tan, U.D. Palanisamy, S.N.A. Malek, W.F. Yin, K.G. Chan, B.H. Goh and L.H. lee: Streptomyces antioxidans sp. nov., a novel mangrove soil actinobacterium with antioxidative and neuroprotective potentials. Front. Microbiol., 7, 889 (2016).

Shan, C., W. Jia Dao, C. Hao Sheng and C. Da Rong: Progress of marine biofouling and antifouling technologies. Chinese Sci. Bull., 56, 596-612 (2011). 
Tan, L.T.H., H.L. Ser, W.F. Yin, K.G. Chan, L.H. Lee and B.H. Goh: Investigation of antioxidative and anticancer potentials of Streptomyces sp. MUM256 isolated from Malaysia mangrove soil. Front. Microbiol., 6, 1-12 (2015).

Tian, X.P., S.K. Tang, J.D. Dong, Y.Q. Zhang, L.H. Xu and S. Zhang: Marinactinospora thermotolerans gen. nov., sp. nov., a marine actinomycete isolated from a sediment in the Northern South China Sea. Int. J. Syst. Evol. Microbiol., 59, 948-952 (2009).

Tsukamoto, S., H. Kato, H. Hirota and N. Fusetani: Antifouling terpenes and steroids against barnacle larvae from marine sponges.
Biofouling, 11, 283-291 (1997).

Xu, Y., H. He, S. Schulz, X. Liu, N. Fusetani and H. Xiong: Potent antifouling compounds produced by marine Streptomyces. Bioresour. Technol., 101, 1331-1336 (2010).

Xu, Y., H. Li, X. Li, X. Xiao and P.Y. Qian: Inhibitory effects of a branchedchain fatty acid on larval settlement of the Polychaete Hydroides elegans. Mar. Biotechnol., 11, 495-504 (2009).

Yebra, D.M., S. Kiil and K. Dam Johansen: Antifouling technology past, present and future steps towards efficient and environmentally friendly antifouling coatings. Prog. Org. Coat., 50, 75-104 (2004). 